\title{
La sombra del poder: Egisto ${ }^{1}$
}

José Vicente Bañuls Oller²

Recibido: 20 de junio de 2016 / Aceptado: 29 de diciembre de 2016

Resumen. El poder, si es efectivo, proyecta una sombra, fenómeno inherente a su necesaria entidad, y en el caso del género de poder que representa Clitemnestra la sombra es de todo punto necesaria, pues su poder precisa de la existencia de Egisto, a la vez que de su no presencia. Intentaremos ahondar en las razones por las que se llega al estado de cosas presente en la Orestea de Esquilo.

Palabras clave: Tragedia; pugna por el poder; Clitemnestra y Egisto; poder efectivo y su sombra.

\section{[en] The shadow of power: Aegisthus}

\begin{abstract}
The power, if it is effective, projects a shadow, phenomenon inherent in his necessary entity, and in the case of the genre of power that represents Clytemnestra shadow it is absolutely necessary, because it requires power from the existence of Aegisthus, while that of their non-presence. We try to delve into the reasons why you come to the present state of affairs in the Oresteia of Aeschylus.

Keywords: Tragedy; power struggle; Clitemnestra and Aegisthus; effective power and its shadow.
\end{abstract}

Cómo citar: Bañuls Oller, J. V. (2017) La sombra del poder: Egisto, en Cuadernos de Filología Clásica. Estudios griegos e indoeuropeos 27, 65-82

1.1. El poder, si es efectivo, si tiene entidad, proyecta una sombra $-\mathrm{y}$ también sombras-, fenómeno que es inherente a la necesaria entidad; en el caso del género de poder que representa Clitemnestra la sombra es de todo punto necesaria, aunque pueda parecer algo contradictorio, pues su poder precisa de la existencia de Egisto, a la vez que de su no presencia. Las razones y el proceso por el que se llega al estado de cosas que presenta la Orestea de Esquilo está ya en la misma saga de los Pelópidas, en su dos ramas en pugna por el poder, la de Atreo y la de Tiestes, en la que desde el principio las mujeres juegan un papel importante.

Egisto, a pesar de gozar de un protagonismo argumental relevante en la saga de los Atridas, de ser el protagonista indiscutible de la que para muchos pasa por ser «la

\footnotetext{
1 El presente trabajo forma parte del proyecto de investigación FFI2015-63836-P de la Dirección General de Investigación Científica y Técnica del Ministerio de Economía y Competitividad.

2 Universidad de Valencia

E-mail: Jose.V.Banuls@uv.es
} 
prima affermazione del libero arbitrio nella storia dello spirito occidentale», ${ }^{3}$ con la que se abre la Odisea como si de una Orestea se tratara, $O d$. 1.28-43, a pesar de ser bien conocidos los sucesos de su discurrir vital y de su destino, a pesar de todo ello, en la tragedia griega, por lo que conocemos, no tiene un desarrollo dramático propio, centrado en él mismo, ni una presencia física en escena importante. Incluso, en el segmento argumental que desarrolla la tragedia en el que la presencia de Clitemnestra y la suya son en principio parejas, su presencia en escena y su acción dramática son obviadas cuando no silenciadas.

Sabido es que Esquilo no escribió un Egisto y, al parecer, Sófocles tampoco, al menos esta es la opinión mayoritaria. Únicamente tenemos constancia fehaciente de la existencia de una tragedia de título Egisto en el caso de los latinos Livio Andrónico y Lucio Accio, ${ }^{4}$ pero una obra de Sófocles con ese título es cuestionada en la actualidad prácticamente por todos, hasta el punto de que Radt en su edición de los fragmentos de Sófocles excluye el único fragmento atribuido a un hipotético Egisto sofocleo, el fr. 26 Pearson, en realidad una hipotética referencia, y lo remite

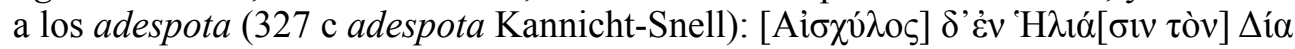

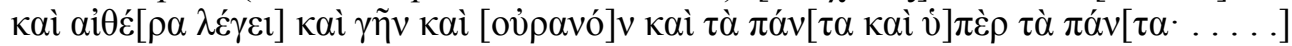

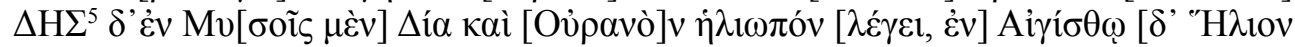

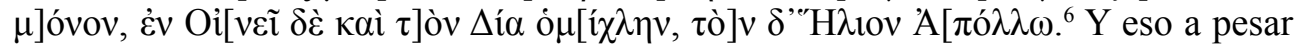
de que Sófocles trató el asunto de Atreo y de Tiestes en dos o tres tragedias, pues en eso tampoco existe un solo parecer, ${ }^{7}$ pero en ellas el protagonismo físico en escena de Egisto se vería muy limitado. ${ }^{8}$

Lesky (1922/1923: 173-182) considera que el Atreo de Sófocles trataría del adulterio de Aérope, del robo del vellocino, seguido de la intervención de Zeus con la inversión del curso del sol y de la marcha al exilio de Tiestes; en el Tiestes se

\footnotetext{
Pasquali (1929: 349).
}

Cf. Pociña (1984: 107-116) y del mismo (2009: 243-270).

5 El texto del papiro en este punto es ilegible. El primer editor conjeturó [Euripid]es, más tarde Wilamowitz, apoyándose en el espacio material disponible, conjeturó [Sófocl]es. Sófocles escribió una tragedia Los misios, y también Esquilo, mencionada por Aristóteles en Po. 1460 a 32, y Agatón compuso una tragedia con el mismo título, y más tarde Nicómaco de Alejandría.

6 [Esquilo] en Las hijas del Sol [llama] a Zeus «éter», «tierra», [《cielo»], "la totalidad de lo que existe»y «lo que está por encima de esa totalidad» [¿Eurípides/Sófocles/..?] en Los misios [llama] a Zeus y a [Urano] "de faz resplandeciente como el sol» [y] en Egisto sólo [al Sol], y en Eneo también a Zeus [«niebla»] y al Sol [Apolo].

7 Cf. la excelente exposición que de este problemático asunto hace Lucas de Dios (1983: 73s. y 116-120).

8 La mayor parte de la crítica considera que las tragedias que escribió Sófocles sobre el tema de Atreo y Tiestes fueron tres. En la primera, Atreo o Las miceneas, se ocuparía del enfrentamiento de los dos hermanos y del banquete abominable; en la segunda, Tiestes en Sición, se ocuparía de las peripecias de Tiestes durante su exilio en Sición, con el motivo del incesto; por último Tiestes II se desarrollaría en Micenas y en ella se produciría el reconocimiento y el cumplimiento del oráculo. Séchan (1926: 199-213) se hace eco de una propuesta de reconstrucción de Petersen (1915: 617-634), que sigue a su vez las líneas generales de la propuesta que Welcker (1839: 357-370) planteara para esta tercera pieza: el prólogo estaría en boca de Pelopia que se lamentaría de su desgracia, ya que sabe al menos que no es hija de Tesproto, sino del infeliz cuya captura ha sido anunciada; tras la párodos harían su entrada Agamenón y Menelao llevando preso al desgraciado que es mandado encarcelar por Atreo; Pelopia intercedería por él, obteniendo de su esposo buenas palabras, pero a continuación éste encarga a Egisto que vaya a darle muerte; en la prisión y a través de la espada que pretende utilizar el joven tiene lugar el reconocimiento; de inmediato corre a comunicárselo a su madre, que, entretanto, ha estado enterándose por el coro de las verdaderas intenciones de Atreo. Pelopia, ya consciente de todo, sale de escena precipitadamente, un mensajero informaría sobre su destino; en este punto la acción final de la obra se precipitaría hacia la venganza que llevaría a cabo Egisto dando muerte a su tío Atreo. En este punto, y dado el carácter de la acción, una acción violenta que ocasiona la muerte, ésta sería narrada por un mensajero, con lo que el protagonismo físico en escena de Egisto se vería muy reducido. 
ocuparía del retorno del exilado, de la muerte de sus hijos y del banquete; por último, en Tiestes en Sición se ocuparía del incesto de Tiestes ${ }^{9}$ y del oráculo de Apolo, del nacimiento de Egisto y su crianza por Atreo y del reconocimiento y muerte de Atreo por Egisto. A Tiestes el oráculo de Delfos le habría dicho que para vengar a sus hijos debía engendrar un hijo en Pelopia, su propia hija, lo que Tiestes en la versión de Sófocles haría sin ser consciente de ello, como se desprende de lo que Higino refiere en su Fab. 88, 3-4; en ella, como anota Boriaud (2003: 178), se observan motivos dramáticos tradicionales: confusión sobre la identidad de los personajes, reencuentro casual en Delfos, reconocimiento final gracias a un objeto, etc. ${ }^{10} \mathrm{Y}$ aunque no aparece con claridad la fuente de Higino, ésta podría haber sido Sófocles, como sugieren algunos, en particular su Tiestes en Sición. ${ }^{11}$

Al parecer Sófocles estructuró la materia de esta saga mítica de modo similar a la de Edipo; no es casual que Aristóteles relacionara a Tiestes con Edipo: ${ }^{12}$ el oráculo, el hijo ignorado, el incesto, la muerte del padre, en un caso el adoptivo, en el otro el biológico, todo ello los aproxima. Pero el motivo más importante, aquél que lleva al error trágico es, como siempre en Sófocles, la ignorancia, el creer hacer una cosa y hacer otra muy diferente, y esto centraría la acción dramática del Tiestes en Sición en el personaje de Tiestes, mientras que Egisto sería el producto del error de Tiestes a la vez que instrumento del oráculo de Apolo. Así, pues, Egisto y Pelopia serían víctimas necesarias para el cumplimiento del destino anunciado, la muerte de Atreo. Realmente ignoramos el protagonismo que pudo tener Egisto en esta tragedia de Sófocles, su presencia en escena, pero si tenemos en cuenta el que tiene en las tragedias conservadas, en el Agamenón y las Coéforas de Esquilo y en las Electras de Sófocles y Eurípides, debió de ser más bien escasa. ${ }^{13}$

La más extensa tiene lugar al final del Agamenón de Esquilo, una aparición inesperada e intempestiva. Eurípides excluye por completo su presencia en escena, que llega únicamente a través del coro, que ha oído su grito de agonía al caer herido de muerte por Orestes fuera de la vista de los espectadores. Pero la escena más

9 En Higino, Fab. 88, 5-7, tenemos el matrimonio de Atreo con Pelopia y el nacimiento de Egisto. Higino confundió al rey de Sición con el rey Tesproto, o al menos se equivoca en la segunda parte de la Fábula en la ubicación de Pelopia. La parte del relato que hace referencia al matrimonio de Atreo y Pelopia y el que Atreo eduque a Egisto como hijo suyo no está en ningún otro mitógrafo.

10 La anagnórisis de Tiestes y Egisto y la muerte de Pelopia y de Atreo la hallamos en Higino, Fab. 88, 8-11. Atreo muere a manos de Egisto, que restablece a Tiestes en el trono. Esto mismo se encuentra en Apolodoro Epit. II 14. Apolodoro añade que después Tindáreo, suegro de Agamenón y Menelao, les restituye en el trono y ponen en fuga a Tiestes (Epit. II 15), pero no aporta detalles, ya que ni menciona el paradero de Egisto ni la muerte de Tiestes; por tanto, queda confusa la sucesión Tiestes-Agamenón sobre todo teniendo en cuenta la enemistad entre las dos ramas.

11 También Eurípides compuso un Tiestes, que, en opinión de Lesky (1922/1923: 173-182) se centraba en el asunto del banquete; su originalidad residía en la caracterización de los hermanos: Atreo era presentado con rasgos sombríos y crueles, mientras que Tiestes, exilado y harapiento, movía a la conmiseración, siguiendo en cierto modo la caracterización de Eteocles y Polinices en sus Fenicias.

12 Aristóteles, Poética 1453 a 7 ss.

13 En Agamenón sólo aparece al final de la obra y de un modo inesperado, con la pretensión por parte del propio Egisto de revestirse del ropaje de héroe trágico esquileo. En Coéforas sale a escena en el v. 838 y tras cruzar unas palabras con la corifeo, en el v. 849 entra en palacio donde es muerto por Orestes. En la Electra de Sófocles Egisto sale a escena en el v. 1442, ya al final de la tragedia, para contemplar el cuerpo sin vida de Clitemnestra, una escena de un gran efectismo dramático, vv. 1466 y ss., y ser él mismo conducido a la muerte, v.1502. En la Electra de Eurípides la presencia de Egisto se limita a un grito oído por el corifeo, vv. 747s., el grito que lanza cuando Orestes le da muerte, grito que es sin duda un eco de los dos gritos que da en Coéforas también desde el interior de palacio al ser abatido. 
dramática y cohesionada con la acción de la obra la hallamos en la Electra de Sófocles, cuando contempla el cuerpo sin vida de Clitemnestra, y es precisamente en la Electra donde recobra en parte los rasgos de carácter que tenía en la Odisea, mientras que Clitemnestra pasa a ocupar un papel más secundario, más acorde a la realidad sociopolítica ateniense, en la línea de la caracterización sofoclea de los personajes femeninos, ${ }^{14}$ aun cuando su muerte a manos de Orestes constituye el núcleo del componente trágico de la obra.

1.2. Las razones del escaso o nulo protagonismo de Egisto se encuentran en su evolución al lado de Clitemnestra, con la que comparte destino, y en la función que esta saga tiene en el imaginario colectivo griego. La evolución de la figura de Clitemnestra desde la épica homérica hasta la tragedia de Esquilo va en la línea de poner de manifiesto que lo que hace vulnerable al ordenamiento político más que su debilidad es la debilidad de los hombres que lo integran, aquellos que le dan su naturaleza. Es precisamente en el canto tercero de Odisea, en unas palabras del relato de Néstor, vv. 262-266, donde podemos ver la dirección que la configuración del conflicto va a ir adquiriendo a la par que se van a ir perfilando sus protagonistas al aproximarse al plano comunitario político e integrarse en el conflicto motivaciones que funcionan en ese plano:

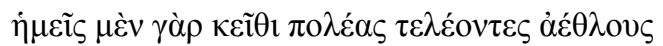

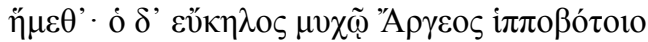

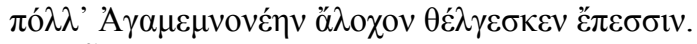

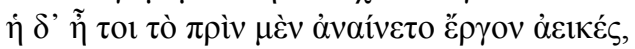
265

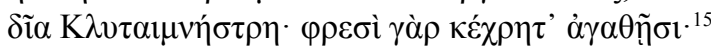

Al principio, según refiere Néstor, Clitemnestra ofrece una resistencia firme y reiterada a las pretensiones no menos reiteradas de Egisto. Y mientras los dioses siembran de obstáculos el camino de retorno a Menelao, Agamenón consigue llegar y es muerto. La eventual llegada de Menelao es presentada por Néstor como una posibilidad de salvación para Agamenón, pero una posibilidad que fatalmente no se dio. Y mientras Menelao deambula por los mares, Egisto urde y consuma el plan, como se lee en los vv. 303-308 del canto 3:

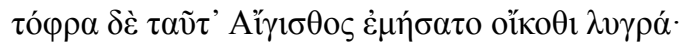

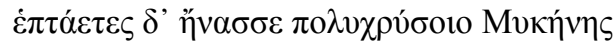

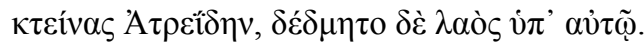

305

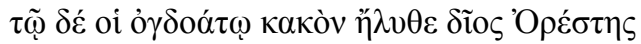

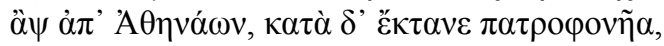

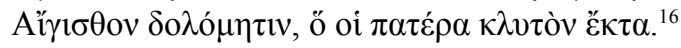

14 El caso de su Deyanira es a este respecto paradigmático, cf. Bañuls \& Crespo (2003: 31-102).

15 Pues nosotros allá soportábamos muchos trabajos; él en cambio, seguro en el interior de Argos, criadora de potros, ponía mucho empeño en seducir a la esposa de Agamenón con sus palabras. Y ella, es cierto, se negaba al principio al hecho infame, la divina Clitemnestra: pues aún disponia de nobles pensamientos.

$16 Y$ mientras Egisto urdió en casa esas cosas penosas; y siete años fue señor de Micenas, rica en oro, después de matar al Atrida, y estuvo sometido el pueblo por él. Al octavo llegó para su mal el divino Orestes desde Atenas, y dio muerte al matador de su padre, al artero Egisto, el que al padre ilustre mató. 
En estos versos del canto 3, en los que se recogen parte de las palabras de Néstor, se nos dice que el autor intelectual y material de la muerte de Agamenón no fue otro que Egisto, algo que escuchamos también en aquel pasaje célebre del comienzo de la Odisea, en el que el propio Zeus se queja de que los mortales hagan responsables a los dioses de cuantas desgracias les sobrevienen, lo que ejemplifica con el asunto de Egisto. Es Egisto, en efecto, tal y como leemos también en el canto 4, vv. 524-526, quien ha dispuesto un vigía, al que ha pagado dos talentos de oro, para que le avise de un eventual regreso de Agamenón, vigía que al divisar a lo lejos a Agamenón y a los suyos se apresura a avisar a Egisto, y es precisamente entonces, como refiere el

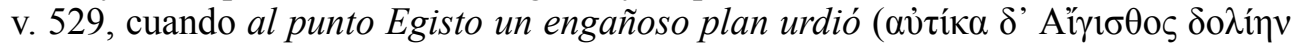
$\dot{\varepsilon} \varphi \rho \alpha ́ \sigma \sigma \alpha \tau o \tau \dot{\varepsilon} \chi \vee \eta v)$. Egisto lleva a su casa a Agamenón, y en sus dependencias, en el curso de una comida, ${ }^{17}$ le da muerte, 4.534-535, y también a los suyos, 4.536, pero en la refriega cayeron también los hombres de Egisto:

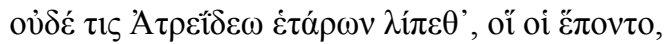

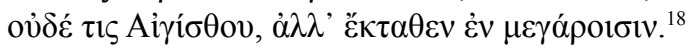

Encontramos más tarde, en $O d$. 11.387-389, en el relato que en la corte de los feacios Odiseo ofrece de sus peripecias, en concreto de lo que le aconteció en una de las puertas del Hades, su encuentro con algunas de las almas de los que aquella noche fueron muertos en forma dolosa:

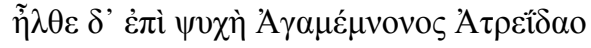

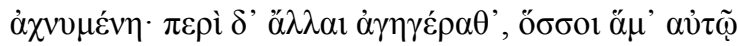
oǐk

87

Y, más adelante, en ese mismo relato del canto 11, en los vv. 409-413, a las preguntas de Odiseo la sombra de Agamenón le da cuenta de las circunstancias que les han llevado a la mansión de Hades, a él y aquellos que compartieron la comida en la mansión de Egisto, una comida con la que se evoca la ofrecida por Atreo a Tiestes:

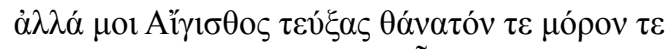

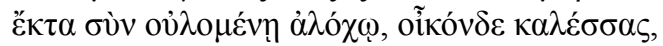

$\delta \varepsilon ı \pi v i ́ \sigma \sigma \alpha \varsigma$,

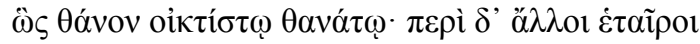

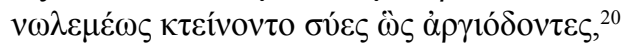

En la descripción de la muerte de Agamenón hallamos una información relevante: de los hombres de Agamenón ninguno quedó con vida, y con ellos cayeron también

17 La mesa ensangrentada y el lecho constituyen sendos hitos recurrentes en esta saga.

18 Ninguno de los compañeros del Atrida quedó, los que le siguieron, ninguno de los de Egisto, sino que murieron en las dependencias.

19 Llegó alli el alma de Agamenón Atrida sumida en tristeza; y a su alrededor otras se reunían, cuantas al mismo tiempo que él en la casa de Egisto murieron y su hado fatal cumplieron.

20 Pero a mi Egisto habiendo tramado no sólo mi muerte sino también mi destino me dio muerte con mi funesta esposa, convocado a su casa, invitándome a la mesa, como quien mata a un buey cara al pesebre. Así fui muerto con la más lamentable muerte; y a mi alrededor otros compañeros de forma encarnizada iban siendo muertos como jabalies de blancos colmillos. 
los hombres de Egisto, vv. 536s. En principio, a partir del momento de la muerte de Agamenón no queda en Micenas hombre alguno que se pueda considerar del Atrida, pero tampoco queda hombre alguno de los de Egisto. Esta circunstancia de forma implícita nos presenta a una Clitemnestra cuya posición personal puede verse fortalecida, mientras que la de Egisto debilitada.

El protagonismo de Clitemnestra en la muerte de Agamenón en principio se debió limitar a una no oposición, lo que estaría de acuerdo con la imagen que de ella nos ofrecen los poemas homéricos, que sitúan en primer plano la muerte de Agamenón a manos de Egisto, con el trasfondo de la infidelidad de Clitemnestra. En no poca medida esto se debe al hecho de haberse servido de ella como el contrapunto negativo de Penélope: a Clitemnestra, la esposa infiel y traidora, se opone Penélope, la esposa irreprochable que, paciente e irreductible a las constantes presiones de los pretendientes, aguarda el regreso del esposo. Pero aún así, en la Odisea está presente la amenaza que para el orden social representa toda mujer, y Penélope lo es, por ello no deja, en consecuencia, de advertirse del peligro que representa. Así, en $O d$. 15.1029, Atenea insta a Telémaco a que regrese ya a Ítaca, y lo hace advirtiéndole del peligro que late en toda mujer, y Penélope, su madre, lo es, no sólo para Odiseo, sino también para él, y, en general, para todos, v. 20: pues sabes qué tipo de pensamientos

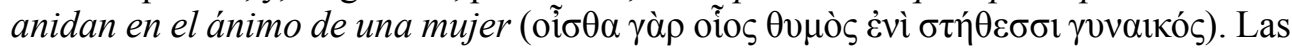
dudas de Telémaco sobre las intenciones de su madre las podemos oír de su propia boca en $O d$. 16.73-76. Además, Atenea había ordenado a Odiseo que no revelase su identidad a nadie, fuese hombre o mujer, Od. 13.310, y Agamenón en el Hades le aconseja que desconfíe de las mujeres, incluso de Penélope, Od. 11.441-456.

El desplazamiento desde Egisto a Clitemnestra del peso mayor en la acción efectiva, esto es, el haber hecho de Clitemnestra la matadora dolosa de Agamenón muy posiblemente se deba a Estesícoro, si bien el desarrollo de la acción de Clitemnestra en ese plano es, sin duda, obra de Esquilo. ${ }^{21}$

Los Nostoi no distinguen su papel del de Egisto, siempre que concedamos crédito al resumen que nos ofrece Proclo 301-302 Severyns: después Agamenón por Egisto

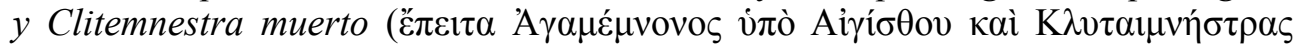

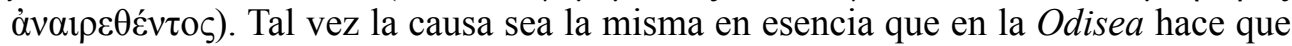
Clitemnestra aparezca como colaboradora de Egisto en la acción de dar muerte a Agamenón. Pero en la Nekyia, en concreto en Od. 11.409s. y 421-423, ${ }^{22}$ el autor material de la muerte de Agamenón es Egisto, mientras que Clitemnestra es quien da muerte a Casandra:

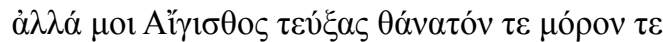

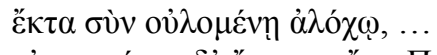

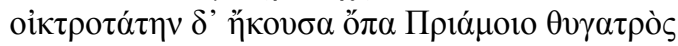

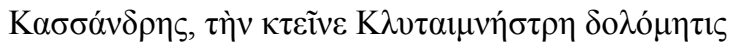

$\dot{\alpha} \mu \varphi^{\prime} \dot{\varepsilon} \mu o{ }^{\prime} \cdot .^{23}$

$21 \quad$ Para las fuentes posibles de las que se sirve Esquilo cf. Moreau (1990: 30-53).

22 En opinión de Severyns (1928: 399-405) se trata de una interpolación inspirada en los Nostoi, en los que la muerte de Agamenón estaría dentro de las consecuencias de los cambios en el poder propiciados por la prolongada ausencia de los expedicionarios, algo de lo que el propio Tucídides nos habla en I 12, 2.

23 Pero a mí Egisto habiendo tramado no sólo mi muerte sino también mi destino me dio muerte con mi funesta esposa (...) oi también la voz más digna de lástima, la de la hija de Príamo, Casandra, a la que mataba la artera Clitemnestra a mi lado. 
Se subraya en ellos el protagonismo de Egisto, pues es él el que da muerte a Agamenón y el que ha tramado su muerte y su destino. La participación de Clitemnestra debió limitarse a una no oposición, a lo que debe hacer referencia

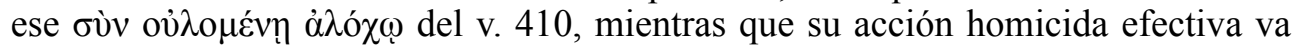
dirigida contra aquello que supone una amenaza a su posición como mujer legítima. Motivación ésta que, sin embargo, la Clitemnestra de Esquilo no activa, al integrarla en el marco general de las aventuras amorosas de Agamenón situando a la hija de Príamo al mismo nivel que todas las Criseidas de las tierras troyanas, X $\rho v \sigma \eta i ́ \delta \omega v$ $\mu \varepsilon i ́ \lambda \imath \gamma \mu \alpha \tau \tilde{\omega} \nu$ i $\pi^{\prime}$ 'I $\lambda i ́ \omega$ (Ag. 1439), ${ }^{24}$ algo que sí hará la Clitemnestra de Eurípides, como ella misma explica en los vv. 1030-1034 de su Electra, rechazando el sacrificio de Ifigenia como motivo.

En la Electra de Eurípides Egisto, aunque su presencia en escena es nula, cobra protagonismo. Y así, las palabras del campesino con el que ha sido casada Electra, nos ofrecen una visión de los hechos que se aproxima a la de los poemas homéricos, como se puede apreciar, p. ej., en los vv. 8-10:

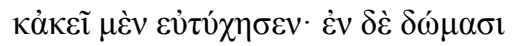

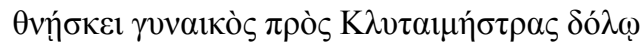

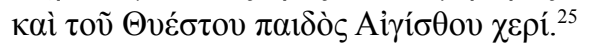

La participación de Egisto y de Clitemnestra en la acción homicida está aquí

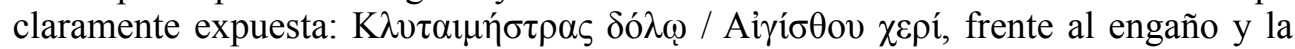
traición, la mano ejecutora, Egisto. El planteamiento de Eurípides presenta puntos de contacto con el planteamiento homérico en lo que respecta a la acción homicida, y mantiene un motivo que es una constante en todo este asunto, en particular en lo que hace a la participación de Clitemnestra, el motivo de la traición y del engaño, $\delta$ ó $\lambda \omega$. El desarrollo de la acción en el plano de los sentimientos es completa, y así el móvil de Clitemnestra para no actuar contra Orestes y Electra es, como nos expone en el prólogo el campesino, el temor a que una acción contra sus propios hijos le granjease la animadversión de la población, ${ }^{26}$ como leemos en los vv. 27-30:

$\kappa \tau \alpha v \varepsilon i ̃ v ~ \sigma \varphi \varepsilon \beta o v \lambda \varepsilon v ́ \sigma \alpha v \tau o \zeta, \omega ̉ \mu o ́ \varphi \rho \omega v$ ö $\mu \omega \varsigma$

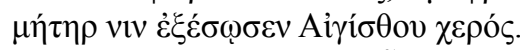

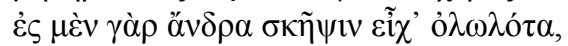

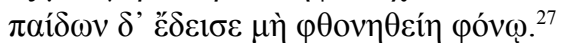

Egisto, que temía que Electra pudiera concebir un hijo que vengara a Agamenón, la tenía encerrada en palacio, pero temeroso de que pudiera eludir la vigilancia y

24 La Deyanira de Sófocles, en cambio, no ve en las infidelidades de Heracles una amenaza para su posición, como ella reconoce, $\operatorname{Tr}$. 459-462, pero la condición de la nueva cautiva hace de ella una amenaza real, como aclara la misma Deyanira, vv. 539-546. Deyanira, en esa situación, intentará recuperar la atracción que ejercía sobre Heracles mediante la pócima que le facilitó el centauro Neso.

${ }_{25} Y$ alli le fue bien; pero en casa fue muerto a causa del engaño de su mujer, Clitemnestra, y a manos del hijo de Tiestes, Egisto.

26 Si bien en ella en ocasiones afloran sentimientos propios de una madre, al igual que en la Clitemnestra de Sófocles.

27 (Egisto) resolvió matarla, sin embargo su madre aunque era cruel la puso a salvo de las manos de Egisto. Pues contra su esposo tenía un pretexto para darle muerte, pero temía dar muerte a sus hijos, no fuese que se granjease el odio por esa muerte. 
concebir en secreto, decidió darle muerte, y sólo los temores de Clitemnestra la pusieron a salvo, como explica el humilde campesino que la recibió como esposa.

De nuevo hallamos a Egisto asumiendo la autoría material y, en esta ocasión, también la intelectual, si bien su plan se verá alterado por los temores de Clitemnestra a las reacciones del pueblo, que la llevaron a persuadir a Egisto para que anulara a Electra desposándola con un humilde campesino, en lugar de hacerlo dándole muerte, y a ofrecer una recompensa a quien diera muerte a Orestes. Pero a pesar del protagonismo de Egisto en la trama y del poder que parece detentar, su presencia física en escena es, como ya hemos indicado antes, nula. Pero éstos son el Egisto y la Clitemnestra de Eurípides, diferentes a los de Esquilo.

Al contrario de lo que sucede con Egisto, la Clitemnestra de Esquilo, desde el comienzo mismo, domina la escena, y ello con independencia de que físicamente se encuentre presente o no ${ }^{28}$. Una Clitemnestra ésta, la de Esquilo, que, como escribe Jufresa (1997: 68), «reúne los dos aspectos, de inteligencia y poder político, que el orden democrático de la polis no puede tolerar en una mujer, ya que los considera una amenaza para su propia existencia.» $\mathrm{Y}$ así es como se nos muestra la Clitemnestra de Esquilo, una mujer que evoluciona desde los poemas homéricos. Pero es en la Electra $^{29}$ de Sófocles donde se recupera en parte la situación que encontramos en la Odisea y donde Egisto tiene la escena más dramática y cohesionada a la acción de la obra. En ella el coro, al evocar la muerte de Agamenón, concluye planteándose en forma de disyuntiva la naturaleza de quien ha llevado a cabo la acción, como vemos en los vv. 197-200:

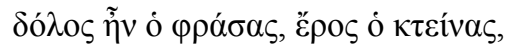

$\delta \varepsilon v \dot{\alpha} v \delta \varepsilon v v \tilde{\omega} \varsigma \pi \rho \circ \varphi \tau \varepsilon v ́ \sigma \alpha v \tau \varepsilon \varsigma$

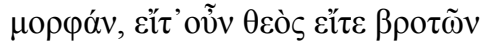

$\tilde{\eta} \nu$ ó $\tau \alpha \tilde{v} \tau \alpha \pi \rho \alpha ́ \sigma \sigma \omega v{ }^{30}$

200

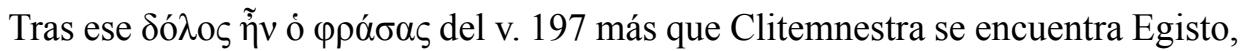
al que se refiere Néstor en $O d .3 .308$ como Aï $\gamma 1 \sigma \theta$ ov $\delta$ o $\lambda$ ó $\mu \eta \tau \imath v$. El coro de la Electra de Sófocles ha introducido aquí el motivo del engaño y de la pulsión erótico-sexual, de cuyos efectos la saga de los Atridas es una buena conocedora, lo que unido a la capacidad de persuasión de Egisto hicieron presa en Clitemnestra. Y así se lo dice Electra a su madre, al comienzo mismo del agón entre ambas, vv. 558-562:

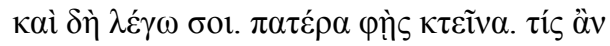

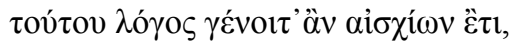

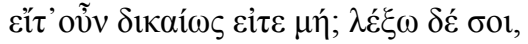

560

28 El contenido de vv. 83ss., en los que el coro, al percatarse de los sacrificios que por doquier se están ofreciendo, interpela a Clitemnestra preguntándole por qué motivo ha dado órdenes para que se lleven a cabo, y, sobre todo, la posibilidad de que Clitemnestra no se encuentre realmente presente, posibilidad admitida por gran parte de la crítica, nos puede dar una idea de la magnitud de su poder y de cómo éste era omnipresente en todo Argos.

29 Las claves de esta tragedia, con el desarrollo de estos dos planos de percepción y acción, las encontramos ya con claridad en su inicio, en el diálogo entre Orestes y el pedagogo, vv. 1-120, por un lado, y en la párodos en forma de comos entre el coro y Electra, vv. 121-250; a este respecto cf. Morenilla \& Bañuls (2008: 187-208).

30 Dolo fue el que urdió, eros el que mató, los cuales terriblemente procrearon terrible forma, ya sea un dios ya sea un mortal el artifice de esto. 


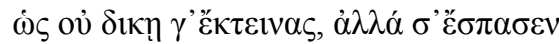

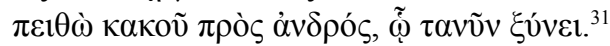

Por boca de Electra retoma Sófocles un rasgo del carácter de Egisto que atraviesa la Odisea partiendo de las quejas del propio Zeus al comienzo del canto 1: el poder de seducción de las palabras de Egisto y su inteligencia dolosa. Y en esa misma línea subraya Electra la responsabilidad de Egisto, ya señalada por Zeus en $O d$. 1.28-43, y en palabras de Néstor en respuesta a Telémaco en 3.254-328, en particular 262-268 y 303-308, antes citados, un Egisto que, como ya hemos visto en 3.264, con frecuencia a la esposa de Agamenón intentaba seducir con palabras

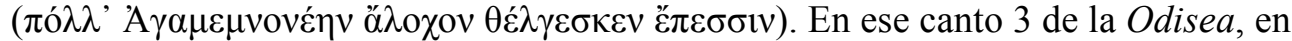
la descripción que Néstor ofrece a Telémaco de las circunstancias de la muerte de Agamenón, la referencia a Clitemnestra tiene además la función de poner de relieve la debilidad de carácter de Egisto, debilidad que facilitará el desarrollo en la Clitemnestra de Esquilo de esos rasgos del carácter femenino tan temidos, el despertar de ese poder tan terrible que anida en el interior del oikos, del que el hombre debe estar siempre vigilante.

El caso 'Egisto-Clitemnestra', tal y como nos cuenta la Odisea, no fue excepcional: la falta de noticias y la ausencia prolongada crearía en no pocos lugares unas circunstancias que desembocarían en un cambio en el poder que conllevaría la muerte de los héroes que lograsen regresar. En Od. 11.380-384, en las palabras con las que Odiseo responde a Alcinoo, que se muestra interesado por la suerte de los compañeros en la expedición contra Troya, encontramos que la suerte de Agamenón estuvo lejos de ser un hecho aislado:

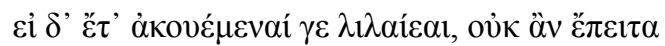
380

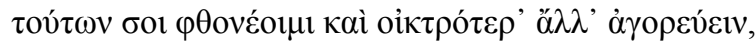

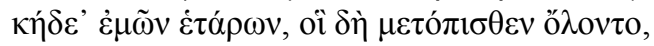

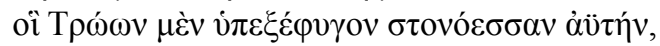

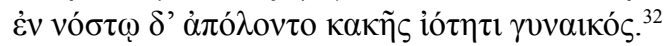

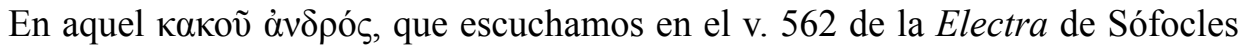
de boca de la propia Electra dirigiéndose a su madre en referencia a Egisto, resuena

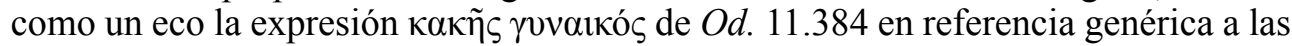
esposas de los héroes muertos al regresar de Troya, lo que nos ayuda a comprender mejor la caracterización del Egisto de la Electra sofoclea.

En esta Electra la posición dominante de Egisto en la casa se ve con claridad a lo largo de toda la obra, así en las palabras que Electra, ya calmada después de la párodos, dirige a las mujeres del coro, vv. 266-274, en las que Egisto aparece como el кúpı́c de la casa, el que no sólo ocupa el lugar y el trono de Agamenón, sino que incluso se reviste con sus ropajes y atributos:

31 Bien, empiezo a hablarte. A mi padre afirmas haber matado. ¿Qué argumento podría haber más vergonzoso aún que éste, lo hicieras con justicia o no? Pero te diré que no con justicia lo mataste, sino que te sedujo la habilidad persuasiva de ese mal hombre con el que ahora convives.

32 Pero si tanto deseas escucharme, no te negaré el contarte otras cosas incluso más dignas de llanto, las desgracias de mis compañeros que, libres apenas del tumulto y clamor del combate con los troyanos, vinieron ya de vuelta a morir por traición de una mala mujer. 


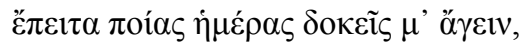

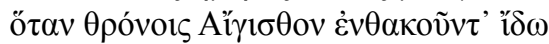

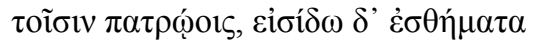

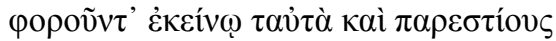

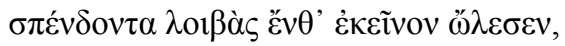

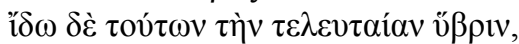

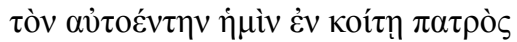

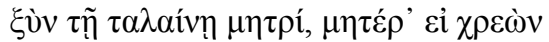

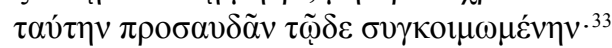

La firme decisión de Egisto de encerrarla en vida, algo que le hará saber Crisótemis en los vv. 379-382, medida similar a la decretada por Creonte para Antígona, pone de manifiesto una vez más a quién corresponde tal decisión, v. 386, quien detenta el poder en Micenas, algo que le será corroborado por Clitemnestra:

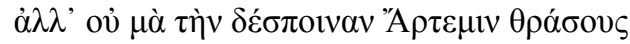

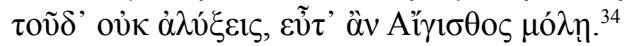

Si la presencia de la Clitemnestra del Agamenón desde el comienzo mismo de la obra se deja sentir dominando por completo la escena incluso no estando presente, el Egisto de la Electra de Sófocles deja sentir incluso a través de su ausencia su poder, como la misma Clitemnestra afirma en el reproche que hace a Electra en las que son sus primeras palabras en escena, vv. 516-520:

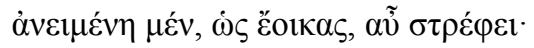

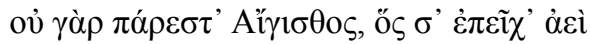

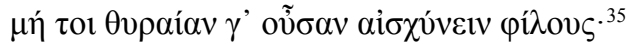

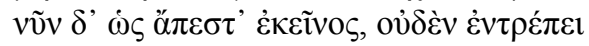

$\dot{\varepsilon} \mu \mathrm{o} \tilde{\gamma} \boldsymbol{\varepsilon} \cdot \ldots^{36}$

El poder de Egisto está presente, pero él no lo está físicamente, como señala

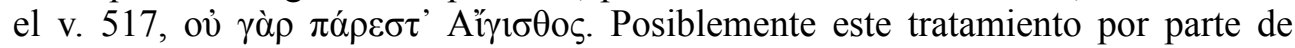
Sófocles de la figura de Egisto en su Electra, unido al hecho de que se le atribuyan tres tragedias sobre el conflicto entre Atreo y Tiestes, además del espacio material disponible en el papiro, debieron inclinar a Wilamowitz a leer «[Sófocl]es» en la

33 ¿Entonces, qué días crees tú que paso yo, cuando veo a Egisto sentado en el trono de mi padre, y le veo llevar las vestiduras mismas de aquél y haciendo libaciones domésticas alli donde le dio muerte, y veo de entre todas la desmesura extrema, al matador en el lecho mismo del padre con la desgraciada madre, si madre se ha de llamar a la que con ése se acuesta?.

34 Pues a fe que, por la dominadora Ártemis, no ha de quedar sin castigo tu atrevimiento tan pronto como llegue Egisto.

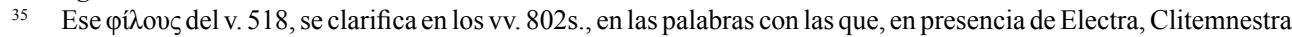

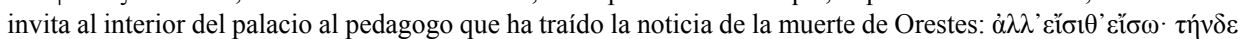

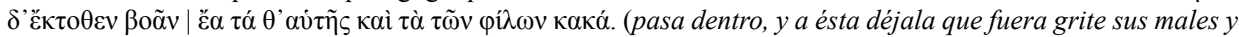
los de los suyos). Es un retorno a la situación de partida, aquella que domina en Odisea, en la que Egisto, vástago de la rama ilegítima, ha desplazado a Agamenón: tras ese $\tau \tilde{\omega} \nu$ $\varphi$ í $\omega \nu$ «de los suyos» se marca con claridad ese desplazamiento.

36 Suelta otra vez, al parecer, vas y vienes, pues no está presente Egisto, que a ti te impide siempre estando en la puerta avergonzar a los tuyos; ahora como está ausente él, nada te cuidas de mí. 
información que transmite Filodemo y que constituye el fr. 327 c Kannicht-Snell adespota, atribución de autoría prácticamente abandonada en la actualidad.

El desarrollo que hace Sófocles del engaño de Orestes, su falsa muerte, permite que Electra se plantee pasar a la acción, y es entonces cuando Egisto pasa a primer plano, pero sólo como el objetivo de la acción, aquella que Electra cree que su hermano tenía que llevar a cabo. ${ }^{37}$ Hasta ese momento Electra sólo ha nombrado a Egisto al comienzo, en su monodia inicial (v. 98), ya que en otros lugares sólo se refiere a él mediante perífrasis. Se propone, pues, Electra dar muerte a quien está ocupando el lugar de su padre, no a Clitemnestra, algo que ya dejó claro en el agón con su madre, vv. 579-584, ${ }^{38}$ y con ello, perdida ya toda esperanza, se propone por encima de todo poner fin a sus sufrimientos de una forma digna, vv. 951-957:

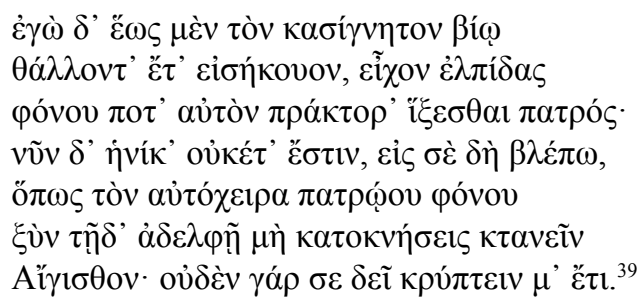

Protagonismo de Egisto, en efecto, pero por completo pasivo y que ni siquiera exige su presencia física en escena, ya que no puede ser muerto a la vista de los espectadores. ${ }^{40}$ Pero en este final, en concreto en los vv. 1482-1484, hay un momento en el que Egisto podía haber cobrado protagonismo si Electra no lo hubiera impedido instando a Orestes a que no le permita hablar: un agón entre Orestes y Egisto, que, por la caracterización de este Orestes, de inmediato hubiera derivado a un agón entre Electra y Egisto. Este agón no sólo hubiera dado protagonismo a Egisto en la acción, sino que hubiera sido el contrapeso dramático del agón entre Electra y Clitemnestra. Pero no fue así, ya que aquella seductora habilidad persuasiva a la que hacía referencia Electra en el agón con su madre (v. 561s.: $\dot{\alpha} \lambda \lambda \dot{\alpha} \sigma$ б'Ě $\sigma \pi \alpha \sigma \varepsilon v \mid \pi \varepsilon \imath \theta \grave{\omega}$

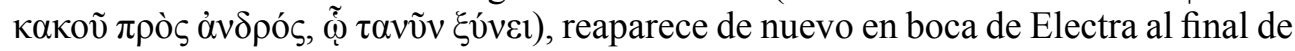

37 El planteamiento de Electra en lo que respecta a la acción necesaria para restablecer el orden justo de las cosas es correcto, y todo estaría bien si la acción la tuviera que llevar a cabo ella; pero la acción efectiva no le corresponde a ella, sino al hombre, a Orestes; y ahí está precisamente la fuente de su error. Y es correcto su planteamiento, porque la acción necesaria, en la forma en que ella la concibe, no genera problema en el derecho de sangre, tal y como ella se lo plantea a Crisótemis, como si de un tiranicidio se tratara, que en otras circunstancias conduciría a la restauración de la casa de Atreo en la persona de Orestes; pero, muerto Orestes, ése ya no es un objetivo posible; y aunque ya no le es posible llevar una vida digna, en sus manos aún queda el alcanzar una muerte digna, una actitud ésta, la de Electra, comparable a la de Ayante, cuando en vv. 473s. exclama: Vergonzoso es para un hombre larga vida anhelar, cuando ésta no ofrece variación alguna en sus desgracias, y finalmente concluye, en los vv. 479s.: Es necesario que el que es de buen linaje o viva gloriosamente o muera gloriosamente.

38 En el agón con su madre, que presenta una estructura judicial muy marcada, como argumentación de que ésta obró mal al intervenir en la muerte de Agamenón, llega a afirmar Electra que el derecho de sangre, esgrimido por Clitemnestra para justificar la muerte de Agamenón, debe superarse, vv. 579-584.

39 Yo mientras oía que nuestro hermano con vida en plenitud de fuerzas estaba, tenía la esperanza de que llegaría como vengador del asesinato de nuestro padre, ahora cuando ya no existe, hacia ti dirijo la mirada, de modo que a la propia mano responsable de la muerte de nuestro padre con tu hermana no rehusarás darle muerte, a Egisto; pues nada es necesario que yo te oculte ya.

40 Y más aún cuando una de las interdicciones dramáticas es la acción violenta que ocasiona la muerte. 
la tragedia, cuando Egisto ya ante el cadáver de Clitemnestra conoce la identidad del que la ha matado y le pide que le deje hablar, pero de inmediato interviene Electra pidiéndole a su hermano que no se lo permita, vv. 1482-1484:

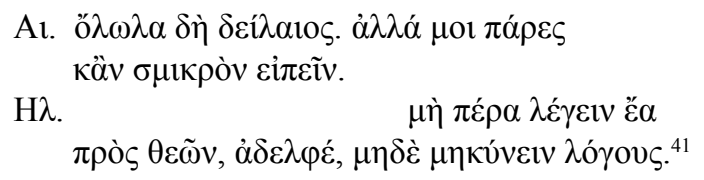

Y en efecto, a Egisto no se le permite hablar. Pero la presencia en escena más larga y sobre todo sonora de Egisto tiene lugar en el Agamenón de Esquilo.

1.3. Al comienzo del Agamenón se nos ofrece a través del vigía y, sobre todo, del coro información sobre Agamenón y las circunstancias en las que inicia y lleva a cabo la empresa contra Troya, y sobre el estado de cosas que se vive en Argos; al final del Agamenón ${ }^{42}$ se nos da información sobre Egisto a través de él mismo, de su discusión con el coro y de la intervención subsiguiente de Clitemnestra, pero se trata de una información que no cuaja en nada más que en una pretensión por parte del propio Egisto de revestirse de modo un tanto burdo el ropaje de héroe trágico esquileo. Con todo, este final constituye en sí mismo un magnífico prólogo a Coéforas, ya que a través de él se proyecta una imagen fiel del estado de cosas que en esencia se va a vivir en Coéforas.${ }^{43}$ Pero no deja de ser un bosquejo, una descripción somera de un carácter, el de Egisto, que se desarrolla fundamentalmente a través de la palabra, no de la acción. Difiere del comienzo del Agamenón en que aquí el personaje caracterizado está presente y es él el que habla. Con todo, la pobreza en la acción despoja a esta parte de lo específicamente dramático, pues, como concluye Aristóteles en referencia a los personajes de las tragedias, éstos no actúan para imitar los caracteres, sino que reciben en conjunto los caracteres a través de sus acciones. ${ }^{44}$

Pero a pesar de todo ello, Egisto se perfila allí con los rasgos fundamentales que hubieran podido dar como resultado un héroe trágico esquíleo. Para comprobarlo basta escuchar sus primeras palabras, corroboradas por el coro, como podemos leer en los vv. 1612-1616:

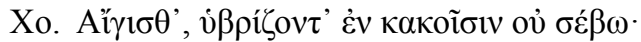

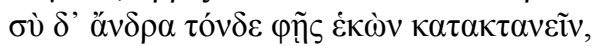

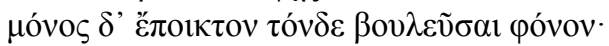

${ }^{41}$ Egisto.- ¡Estoy perdido, desgraciado! Pero déjame hablar siquiera un poco. Electra.- No le permitas hablar más aún, por los dioses, hermano, ni que alargue la conversación.

42 «La pièce aurait pu s'achever avec le dialogue lyrique du Chœur et Clytemnestre, qui aurait ainsi servi d'exodos (final, avant la "sortie" des acteurs). L'entrée, totalment inattendue, d'un nouveau personage créée une scene supplémentaire, "en plus", dont le ton et le langage tranchent brutalement avec le reste du drame, qui reste comme sans conclusion», puntualiza Judet de la Combe (2015: 258s.), y con más detalle (2001: 715770). Pero más que quedar sin conclusión lo que indirectamente aporta es una visión de conjunto del estado de cosas que se vivirán en el Argos de Coéforas, el Argos sobre el que ya no planea la sombra del retorno de Agamenón.

43 Sobre este final cf. también Albini (1981: 217-219).

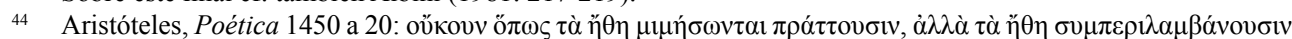
$\delta$ ì̀ $\tau \grave{\alpha} \varsigma \pi \rho \alpha ́ \xi \xi ı \iota$. 


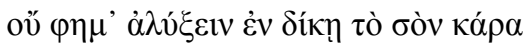

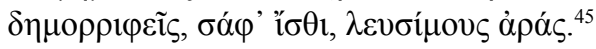

Y así es, pues Egisto se ha jactado de haber urdido y llevado acabo la muerte de Agamenón. Sus palabras y su posicionamiento ante los hechos le habilitan plenamente, aunque de una forma un tanto precipitada y esquemática, para asumir el protagonismo en una tragedia de Esquilo, incluso manteniendo una de sus constantes personales, la de tener escasa presencia física en escena, como también es el caso del Jerjes de Persas. Ambos, Egisto y Jerjes conocen el destino que pesa sobre ellos; a Egisto le fue anunciado por Zeus, que le envió a Hermes para que le advirtiera de que no pretendiera a la mujer del Atrida ni le diera muerte, ya que Orestes cuando fuera en edad lo mataría; sobre Jerjes pesa un oráculo de $\mathrm{Bacis}^{46}$, que late en las premonitorias palabras de Artábano, quien en el Consejo convocado por Jerjes, previo a la campaña helénica, entre las objeciones planteadas, le recuerda del inmenso peligro a que estuvo sometido el ejército persa en la campaña contra los escitas, en la que también se tendieron puentes sobre las aguas ${ }^{47}$. Las palabras que cruzan la sombra de Darío y su esposa Atosa nos hablan ya de ello. Se trata de un pasaje bien conocido de los Persas de Esquilo, en el que la reina responde a las preguntas que le va formulando la sombra de su esposo acerca de lo sucedido a los ejércitos persas; en este cruce de preguntas y respuestas, la sombra de Darío se interesa por el modo como Jerjes llevó a cabo el paso del Bósforo:

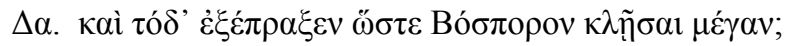

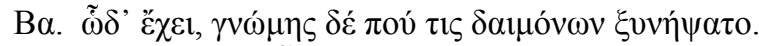

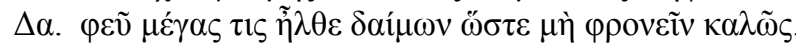

$\Delta \alpha . \varphi \varepsilon \tilde{v} \tau \alpha \chi \varepsilon \tilde{\imath} \dot{\alpha} \gamma^{\prime} \tilde{\eta} \lambda \theta \varepsilon \chi \rho \eta \sigma \mu \tilde{\omega} \nu \pi \rho \tilde{\alpha} \xi 1 \zeta, \grave{\varepsilon} \varsigma \delta \grave{\varepsilon} \pi \alpha \tilde{\delta} \delta^{\prime} \dot{\varepsilon} \mu o ̀ v$

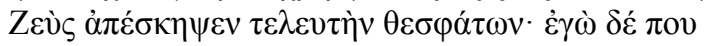

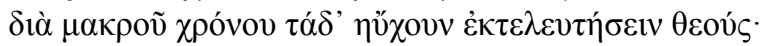

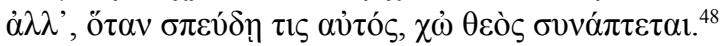

45 Coro.- Egisto, por el que es presa de desmesura en las desgracias no siento respeto: tú a este hombre afirmas, deseando hacerlo, haberle dado muerte, y solo este doloroso asesinato haber ideado; yo afirmo que, cuando se haga justicia, tu cabeza no salvarás de las imprecaciones de lapidación, sábelo bien, arrojadas por el pueblo

46 Bacis, un adivino legendario (cf. Ar. Pax 1071; Pausanias, IV 27, 4; 12, 11) a quien se atribuía una colección de oráculos, similar a los que se consideraban emitidos por Orfeo y Museo. El oráculo de Bacis contrario a los Persas es recogido por Heródoto en VIII 77.

47 Heródoto VII 10 e.

48 Dario.- ¿Y lo hizo hasta el punto de cerrar al gran Bósforo? Reina.- Así es, sin duda a su pensamiento alguna de las deidades le ayudó. Dario.- ;Ay, una gran deidad le llegó de modo que no pudo discurrir bien!. (...) ;Ay, pronto, sí, vino la acción de los oráculos, y sobre mi propio hijo Zeus hizo caer el cumplimiento de las palabras divinas! y yo hacía preces porque después de largo tiempo les dieran cumplimiento completo los dioses: pero cuando se apresura uno mismo, también la divinidad le ayuda. Aunque en Sófocles las más de las veces no sea tan patente la intervención de la divinidad, al menos en su calidad de garante del orden justo de las cosas,

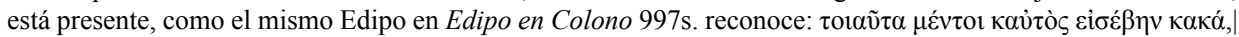

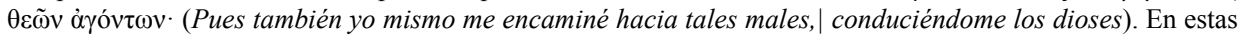
palabras de Edipo, consciente ya de quién es y de lo que ha hecho, resuenan las que hemos escuchado a la sombra de Darío, en las que la interacción entre el plano divino y humano se pone de manifiesto con claridad. Los vv. 724s. son clave para entender la interacción entre ambos planos en esta tragedia de Esquilo: la divinidad

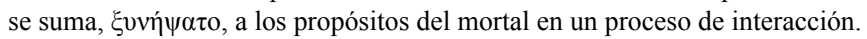


La ignorancia, la ausencia de consciencia que caracteriza a los héroes de Sófocles, en los de Esquilo está ausente, pues son de algún modo conscientes ${ }^{49}$ de lo que hacen. Tras ese غ̇кஸ̀v del v. 1613 del Agamenón se explicita lo que mejor define al héroe esquileo: el ser consciente de lo que hace, aun cuando su consciencia esté alterada en algo por una tendencia a tomar el camino erróneo que define la naturaleza de su linaje. Y frente a él el héroe sofocleo, que, aunque conoce y reconoce la autoría de los actos realizados por él, los llevó a cabo desde la ignorancia, como podemos escuchar, por seguir el parangón con Edipo, en boca de éste, consciente ya y sabedor de todo, en OC. 962-964:

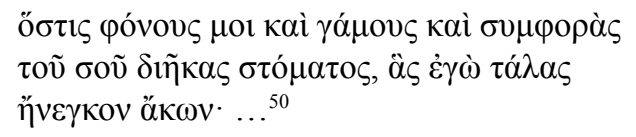

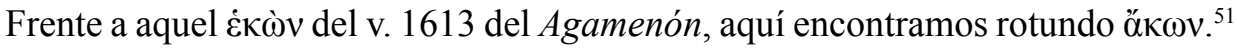
Esta característica facilita la adopción por parte de Sófocles de los avatares de Tiestes, pues su acción parte y se desarrolla en la ignorancia, pero no las de Egisto, un instrumento del destino. Una razón más que lo inhabilitan como protagonista de una tragedia de Sófocles.

2. Las razones del escaso o nulo protagonismo de Egisto sin duda se encuentran en su evolución al lado de Clitemnestra, con la que comparte destino, y en la función que esta saga mítica tiene en el imaginario colectivo griego. La evolución de la figura de Clitemnestra desde la épica homérica hasta la tragedia de Esquilo va en la línea de poner de manifiesto que lo que hace vulnerable al ordenamiento político más que su propia debilidad es la debilidad de los hombres que lo conforman, aquellos que le confieren su entidad y su naturaleza, rasgo de carácter que hallamos en Tiestes y en Egisto, y que va aflorando en diferentes formas también en la otra rama en Orestes.

Del Atreo de Sófocles, conocida también por Las miceneas, título transmitido por la tradición y que haría referencia a las mujeres del coro - lo que lleva a pensar que en esta obra posiblemente el papel de Aérope, la esposa de Atreo, debió de ser importante en la acción dramática-, nos ha llegado un fragmento de especial interés, ya que aproxima el carácter de Tiestes y Egisto, fr. 140 Radt:

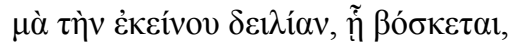

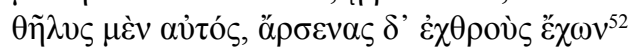

Palabras éstas referidas a Tiestes, al menos esa es la opinión mayoritaria, que al igual que su hijo Egisto, tiene una naturaleza poco masculina y se sirve también

49 Cf. a este respecto Bañuls \& Crespo (2007: 17-71), y Bañuls \& Morenilla (2008: 73-87).

50 Tú que homicidios y maridajes y desventuras me vas propagando desde tu boca, lo que yo, desgraciado, llevé a cabo no deseándolo.

51 Ningún héroe trágico sofocleo lleva a cabo la acción por la que alcanza la condición de trágico Ékஸ̀v. Desde Ayante, al que ciega Atenea, pasando por Creonte, no consciente del alcance de su decreto, Deyanira, ignorante del efecto de la pócima que le diera el centauro Neso, todos ignoran y en ellos no hay maldad, sino ignorancia, en un posicionamiento generacional que Sófocles comparte con Sócrates.

${ }_{52}$ ¡No, por la cobardia de aquél, con la que se nutre, pues femenino es él, pero con hombres como enemigos! 
de las mujeres para sus fines, en su caso de Aérope, ${ }^{53}$ con lo que tendríamos una continuidad en la caracterización de padre e hijo. La introducción de Electra en la acción facilita el desarrollo en Orestes de ese rasgo, que alcanzará su punto más alto en la Electra de Eurípides, en la que precisa de la ayuda física de Electra para asestar el golpe a Clitemnestra. Posiblemente tras la caracterización casi mecánica y fría del Orestes de la Electra de Sófocles también se esconda esa debilidad de carácter a la vez que el compartir este Orestes con Egisto otro rasgo, el ser él mismo la encarnación de una orden de Apolo, pues por designio de Apolo Egisto será el instrumento necesario para vengar a los hijos de Tiestes, muertos por Atreo, y Orestes lo será para vengar a su padre Agamenón.

La historia de Egisto, que podía dar mucho de sí, se queda en un pretender sin llegar a nada, anulado por una mujer con un carácter y una fuerza notables, una mujer que, paradójicamente, en la Odisea desempeña al igual que Egisto un papel subsidiario en tanto que es el contrapunto de Penélope, hasta el extremo de que no ha faltado quien ha visto en esa función su única razón de ser en la obra. Las andanzas de Odiseo, paradigma de los accidentados regresos de los héroes que secundaron a Agamenón y Menelao en la campaña, centran el eje argumental de este poema épico en el que coexisten las diferentes sagas míticas de esos héroes, instrumentalizadas en mayor o menor medida en aras del eje temático central focalizado en Odiseo y los suyos. El poema en sí nos habla de los peligros que en el discurrir vital acechan amenazantes al hombre, los más de ellos de género femenino, circunstancia que enlaza perfectamente con la función que la saga de los Atridas tiene en el imaginario colectivo griego, lo que explica el desarrollo subsidiario que en la Odisea tiene lo referente a esta saga. Pero una vez centrada la trama en el regreso y muerte de Agamenón, liberados Clitemnestra y Egisto de esa subsidiaridad, el protagonismo de Egisto cederá ante Clitemnestra en aras de su función primordial: reafirmar la supremacía del padre sobre la madre y el carácter exclusivamente patrilineal del poder y de la sociedad en la que se sustenta. Esa función, presente también en la Odisea, aunque no en una forma tan señalada como en la Orestea, explica el papel de la saga de los Atridas en ella frente a las restantes sagas. No en vano la Odisea advierte también del peligro que la mujer representa y que potencialmente lleva en sí misma, advertencia que debe tener presente el mismo Odiseo, incluso en lo que hace a Penélope, algo de lo que le advierte un más que escarmentado Agamenón, ya muerto, en Odisea 11. 441-456:

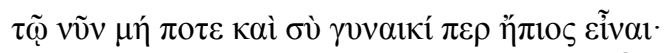

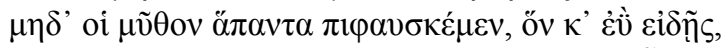

$\dot{\alpha} \lambda \lambda \dot{\alpha} \tau$

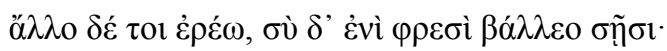

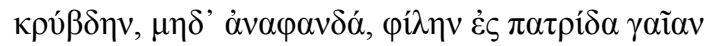

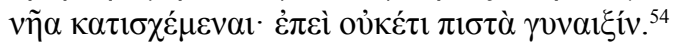

53 E incluso de su propia hija, aun cuando en este caso por medio andaría el oráculo de Apolo.

54 Ahora, pues, tú con tu mujer no seas condescendiente; y no le des cuenta de todo aquello que sepas, sino dile unas cosas, pero otras también mantenlas ocultas. (...) Otra cosa te diré, y tú en tu mente retenla: a escondidas, y no al descubierto, hacia tu tierra patria la nave dirige: puesto que ya no hay motivos de confianza en las mujeres. 
El progresivo desplazamiento desde Egisto hacia Clitemnestra no sólo de la acción efectiva de dar muerte a Agamenón, sino también de haber tramado su muerte lo podemos observar ya en la Odisea, al comparar aquellos pasajes, como el que abre este poema épico, con otros en los que ya se observa ese desplazamiento hacia Clitemnestra y que, sin duda, apuntan al deseo de reafirmar la naturaleza masculina de la comunidad política subrayando el peligro siempre latente que para ella representa la mujer. En ese contexto el papel de Egisto es necesariamente instrumental en aras del protagonismo de Clitemnestra y del fin último de la saga en el imaginario griego.

Un factor que contribuye a explicar el escaso o nulo protagonismo efectivo de Egisto es la introducción de Electra y el sacrificio de Ifigenia como motivación de Clitemnestra. La Odisea nos muestra a una mujer seducida, que llega a ser un cómplice más o menos pasivo de su seductor, estableciéndose de ese modo una cierta analogía entre las dos parejas, Egisto-Clitemnestra, por un lado, y ParisHelena, por otro, y frente a ellas Agamenón y Menelao, y todo ello como contraste con la pareja Penélope-Odiseo. En la Pítica 11 de Píndaro, vv. 19-25, encontramos ya el motivo de la venganza por la muerte de Ifigenia, si bien Píndaro lo plantea dentro de una posible alternativa con la motivación tradicional, que de todos modos no queda excluida:

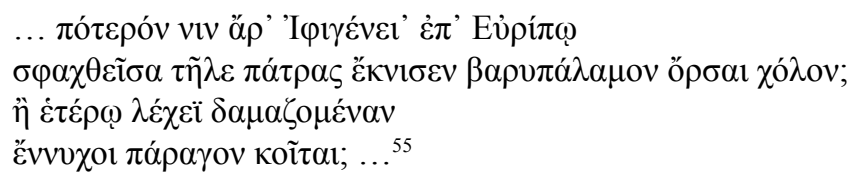

Píndaro, aunque duda sobre la verdadera motivación de Clitemnestra y se plantea dos posibilidades, parece inclinarse por la segunda. Con todo, al entrar en juego el sacrificio de Ifigenia como motivación de Clitemnestra, se inicia el desplazamiento desde Egisto a Clitemnestra del peso de la acción homicida, que encontramos ya completado en Esquilo, así como la introducción plena de un segundo personaje femenino, Electra, contrapeso dramático de Clitemnestra, lo que refuerza su protagonismo en detrimento del de Egisto. Además, Píndaro nos presenta a un Orestes ejecutor de la acción, a la vez que sitúa en primer plano la muerte de Clitemnestra; Egisto cae también, claro está, pero su muerte es presentada como un hecho secundario, casi incidental, vv. 36s.:

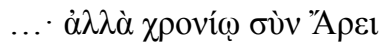

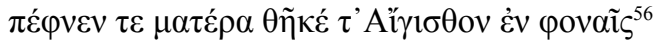

Con ello, en cierto modo, tendríamos aquí un antecedente de la inversión en el orden de las muertes que presentará Sófocles en su Electra y también de la forma en que es presentada la muerte de Egisto, casi sin relevancia, pues al final en la tragedia de Sófocles se lo llevan poco menos que a la ejecución de la pena capital como magnicida que es.

\footnotetext{
55 ¿Acaso Ifigenia, a orillas del Euripo degollada, lejos de su Patria, la irritó hasta el punto de suscitar la cólera de su pesada mano? ¿O bien, sometida a otro lecho, nocturnas uniones la hicieron desvariar?.

56 Pero con el tiempo, con la ayuda de Ares (Orestes) dio muerte a su madre y postró a Egisto en la matanza.
} 
Como vamos viendo, muchas son las razones del mantenimiento de Egisto en la sombra, pero todas tienden a girar en torno a la función que esta saga tiene en el imaginario colectivo griego, pues los sucesos de esta saga mítica, los roles de sus personajes ${ }^{57}$ y su estructuración interna, están tan firmemente fijados en él que difícilmente podrían modificarse para dar a Egisto un protagonismo más allá del que tiene desde Esquilo, el de ser un instrumento necesario para los fines de Clitemnestra. Y hasta tal punto esto es así que en el segmento de la saga que encontramos dramatizado en los tres trágicos, en Coéforas y en las dos Electras, el que hace referencia a la recuperación del poder por parte de Orestes, aunque Sófocles y Eurípides introducen cambios relevantes, no cambian en lo fundamental la trama y se sirven de él no para plantear el problema de la naturaleza patrilineal del poder y de la sociedad, aun cuando está latente en el argumento.

Sófocles y Eurípides se sirven de este material mítico, pero lo hacen con unas finalidades diferentes a las de Esquilo. En Eurípides ${ }^{58}$, al igual que en Esquilo, la legitimidad de Orestes queda cuestionada por el hecho de haber dado muerte también a su propia madre, por lo que la intervención divina finalmente se hace necesaria: al final del Orestes Apolo le comunica lo que debe hacer y le señala el camino de la solución definitiva, que no es otro que el que conduce a Atenas. Y en el caso de Sófocles, aunque la alteración del orden de las muertes subraya la transgresión de Orestes, no se hace necesaria intervención alguna de la divinidad, pues, como concluye el coro, vv. 1508-1510:

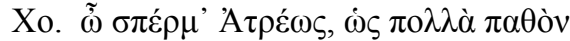

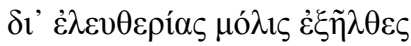

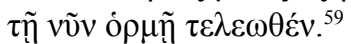

¿Y a qué golpe se refiere? sin duda al último, conducir a Egisto al interior de palacio para ser ejecutado, pues así es conducido por Orestes. Pero de la muerte de Clitemnestra nada se dice y nada hay que purificar, pues ésta es la tragedia de Electra, la que comete el error trágico que la hace partícipe de la muerte de su propia madre $^{60}$. Y en todo ello Egisto una vez más es imprescindible, pero en la sombra, la sombra del poder que es Clitemnestra.

57 Una de las razones del mantenimiento de Egisto en un segundo plano, cuando ya no funciona Clitemnestra como contrapunto de Penélope, es la activación de una de las funciones que esta saga mítica lleva en sí misma, en su propia trama argumental, pues es una saga plagada de mujeres nada aconsejables.

58 En ambas Electras la posición del oráculo de Delfos es relevante y va desde una ambigüedad buscada, como señala Fialho (2007) 39-52, caso de Sófocles, a una instrumentalización abierta, caso de Eurípides, como muestran Bañuls \& Crespo (2003)103-118; denuncia Eurípides la instrumentalización de mecanismos religiosos, en particular del oráculo de Delfos, y del propio imaginario colectivo por parte de los sectores antidemocráticos que darán el golpe del 411.

59 ¡Oh, semilla de Atreo, cómo, después de haber sufrido mucho, a la libertad finalmente te has abierto camino habiendo con el golpe de ahora llegado al final!

60 Sófocles la presenta fuera del contexto del derecho de sangre, pero no la traslada, como hace Esquilo, a un tribunal de la polis o, como hace Eurípides, a una Asamblea popular y finalmente, en el Orestes, por la intervención de Apolo a Atenas, a las Euménides, que lo absolverán en el tribunal del Areópago. No hace nada de esto Sófocles, pero tampoco hace otra cosa, sencillamente cambia el orden de las muertes poniendo la muerte de Clitemnestra de forma inesperada en un primerísimo plano y la deja sin consecuencias para Orestes, con lo que su muerte adquiere la naturaleza convencional de un motivo dramático necesario para que el error de apreciación de Electra alcance la condición de trágico. 


\section{Referencias bibliográficas}

Albini, Umberto (1981), «Egisto nel finale dell'Agamemnone», en Schmidt (1981: 217-219). Bañuls, José Vicente \& Crespo, Patricia (2003), «La arquitectura de la heroína trágica en Sófocles», en De Martino \& Morenilla (2003: 31-102).

- (2003), «Electra, la tejedora de destinos», en De Martino \& Morenilla (2003: 103-118).

- (2007), «El conocimiento en la configuración del héroe esquileo», en Bañuls, De Martino \& Morenilla (2007: 17-71).

Bañuls, José Vicente, De Martino, Francesco \& Morenilla, Carmen (eds.) (2007), El teatro greco-latino y su recepción en la tradición occidental 2, Bari: Levante Editori.

Bañuls, José Vicente \& Morenilla, Carmen (2008), «Rasgos esquileos en la caracterización de algunos personajes sofocleos», $C F C$ (g) 18: 73-87.

Boriaud, Jean Yves (2003), Hygin. Fables, Paris: Les Belles Lettres.

De Martino, Francesco \& Morenilla, Carmen (eds.) (2003), L'ordim de la llar, Bari: Levante Editori.

- (eds.) (2009), Teatro y sociedad en la Antigüedad Clásica: Legitimación e institucionalización política de la violencia, Bari: Levante Editori.

Fialho, Maria do Céu (2007), «O deus de Delfos na Electra de Sófocles», Minerva 20: 39-52.

Judet de La Combe, Pierre (2001), L'Agamemnon d'Eschyle. Commentaire des dialogues, Villeneuve d'Ascq: Septentrion PU.

- (2015), Eschyle, Agamemnon, Paris: Les Belles Lettres.

Jufresa, Montserrat (1997), «Clitemnestra y la justicia», en Rodríguez Magda (1997: 63-76).

Lesky, Albin (1922/23), «Die griechischen Pelopidendramen und Senecas Thyestes», WS 43: 173-182.

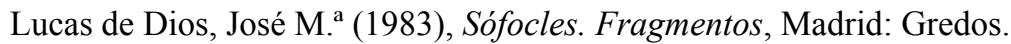

Moreau, Alain (1990), «Les sources d'Eschyle dans 1' Agamemnon: silences, choix, innovations», $R E G$ 103: 30-53.

Morenilla, Carmen \& Bañuls, José Vicente (2008), «Una aproximación a la Electra de Sófocles desde el prólogo y la párodos», Faventia 30/1-2: 187-208.

Pasquali, Giorgio (1929), «La scoperta dei concetti etici nella Grecia antichissima», Civiltà Moderna I: 343-362.

Petersen, Eugen Adolf Hermann (1915), Die attische Tragödie als Bild- und Bühnenkunst, Bonn: Verlag Friedrich Cohen.

Pociña, Andrés (1984), El tragediógrafo latino Lucio Accio, Granada: Universidad de Granada.

- (2009), «Tiranía y violencia: Atreo en el Atreus de Accio y en el Thyestes de Séneca», en De Martino \& Morenilla (2009: 243-270).

Rodríguez Magda, Rosa María (ed.) (1997), Mujeres en la historia del pensamiento, Barcelona: Anthropos.

Séchan, Louis (1926), Études sur la tragédie grecque dans ses rapports avec la céramique, Paris: Champion.

Severyns, Albert (1928), Le Cycle épique dans l'école d'Aristarque, Liège \& Paris: VaillantCarmanne \& Champion.

Schmidt, Ernst Günther (ed.) (1981), Aischylos und Pindar. Studien zu Werk und Nachwirkung, Berlin/DDR: Akademie-Verlag.

Welcker, Friedrich Gottlieb (1839), Die griechischen Tragödien mit Rücksicht auf den epischen Cyclus geordnet, I, Bonn: E. Weber. 